\title{
O Antes e o Depois: Expectativas e Experiências de Mães sobre o Parto
}

\author{
Rita de Cássia Sobreira Lopes \\ Tagma Schneider Donelli \\ Carolina Mousquer Lima \\ Cesar A. Piccinini ${ }^{1}$ \\ Universidade Federal do Rio Grande do Sul
}

\begin{abstract}
Resumo
O parto representa um marco na vida da mulher, repercutindo profundamente nos seus planos físico, emocional e social. Antecipado na gestação, nas fantasias da mulher, continuará sendo revivido nas lembranças da mãe. O presente estudo longitudinal investigou as expectativas e o posterior relato da experiência do parto de 28 mulheres primíparas, com idades entre 20 e 37 anos. Entrevistas individuais foram realizadas no $3^{\circ}$ trimestre de gestação e 3 meses após o parto. Análise de conteúdo qualitativa indicou que as mães relatam, durante a gestação, tanto expectativas positivas como negativas em relação ao parto, seja no que diz respeito a si própria quanto ao bebê. Já em relação à experiência do parto, houve uma tendência à polarização, com algumas mães relatando apenas sentimentos positivos e outras apenas sentimentos negativos. Apoiando a expectativa inicial do estudo, os relatos mostram que o parto se constitui em um evento que perpassa todo o processo de gestação e puerpério, marcando profundamente a história da mãe.

Palavras-chave: Gestação, parto, maternidade.
\end{abstract}

Before and After: Expectations and Experiences of Mothers Concerning Labour

\begin{abstract}
Labour represents an important event in a woman's life, having a deep impact on the physical, emotional and social domains. It is anticipated during pregnancy, in the woman's fantasies and will be relived in the mother's memories. The present longitudinal study investigated the expectations and the later report of the labour experience of 28 primiparous women, aged 20 to 37. Individual interviews were carried out during the $3^{\text {td }}$ trimester of pregnancy and 3 months after labour. Qualitative content analysis indicated that mothers reported, during pregnancy, both positive and negative expectations regarding herself and the baby during labour. As far as labour experience is concerned, there was a trend towards polarization, with some mothers reporting only positive feelings whereas others reported only negative ones. Supporting the initial expectation of the study, the results show that labour is an event which encompasses the whole process of pregnancy and postpartum having a deep impact on the mother's history.

Keywords: Pregnancy; labour; motherhood.
\end{abstract}

O parto é uma experiência extremamente importante na vida de uma mulher. A experiência de dar à luz é tão marcante que, durante anos, o evento e os sentimentos experimentados durante o nascimento do bebê serão lembrados nos mínimos detalhes (Kitzinger, 1987). O parto, por sua natureza, não é um evento neutro - ele tem força para mobilizar grandes níveis de ansiedade, medo, excitação e expectativa e, por sua intensidade, pode ajudar na reformulação da identidade da mulher (Peterson, 1996).

O parto pode ser considerado um momento importante do processo de transição para a maternidade, por inúmeras razões. Em primeiro lugar, é o momento em que mãe e bebê vão, finalmente, poder se encontrar frente a frente (Lebovici, 1987). Para a mulher, é o momento de se deparar com o bebê real, que gestou por 9 meses, e que provavelmente será diferente do tão sonhado bebê imaginário, idealizado durante a gestação (Raphael-Leff, 1997). Também é o momento de se deparar com um produto seu, do seu corpo, que mostrará para o mundo sua capacidade ou incapacidade feminina de gerar uma criança. É hora, portanto, de pôr à prova sua competência feminina de gerar, sua competência materna de cuidar, e sua competência física de suportar as dores, resistir à retaliação de seus órgãos genitais e,

\footnotetext{
${ }^{1}$ Agradecemos ao CNPq pelo apoio financeiro concedido para realização do presente estudo.Endereço para correspondência: sobreiralopes@portoweb.com.br
}

ainda, nutrir seu filho através da amamentação (Peterson, 1996; Simkin, 1991; Stern, 1997). Além disso, o nascimento de um filho, principalmente do primeiro, inaugura definitiva e concretamente a maternidade, e esse fato vem acompanhado de todo o status e toda a pressão social do papel de mãe. A mulher se vê obrigada a abandonar seu papel de filha e assumir o de mãe (Brazelton \& Cramer, 1992; Klaus \& Kennell, 1993). Mas o parto também dá à mulher a oportunidade de reviver seu próprio nascimento e de renascer como mulher, além de nascer como mãe (Birksted-Breen, 2000; Maldonado, 1994; Maldonado, Dickstein \& Nahoum, 1996).

Na verdade, o parto é, por si só, um evento de significância psicológica incontestável, e não apenas o meio pelo qual homens e mulheres se tornam pais (Fisher, Astbury \& Smith, 1997). A potencialidade para acarretar benefícios ou danos psicológicos está presente em cada parto e, portanto, há mais envolvido no processo do que a saúde e integridade física da mãe e do bebê. Segundo estes autores, as memórias sobre o parto permanecem vivas em nível cognitivo e psicológico, e continuam influenciando as percepções da mulher sobre a experiência por muito tempo. Sendo assim, o parto, especialmente do primeiro filho, exerce um impacto, positivo ou negativo, que repercute durante sua vida inteira (Simkin, 1991, 1992).

A experiência do parto é influenciada por vários fatores, dentre os quais, destacam-se os procedimentos obstétricos, os cursos de 
preparação pré-natal, a história obstétrica anterior, bem como o desfecho de uma gravidez prévia (Fisher \& cols., 1997). Outros autores também apontaram para o impacto do tipo de parto e das intervenções obstétricas sobre a experiência do parto (Mercer, Hackley \& Bostrom, 1983). Além desses fatores, a própria gestação e as expectativas alimentadas em relação ao parto e ao bebê durante esse período podem influenciar a maneira como o parto será experienciado (Maldonado, 1994). Os temores mais comuns da gravidez têm relação estreita com as fantasias que surgem no período final da gestação. Para Soifer (1992), o temor à morte, à dor, ao esvaziamento e à castração, são temas típicos das fantasias desse período.

A ansiedade durante a gestação está associada com uma posterior vivência negativa da experiência do parto (Waldenström, 1999). Ela é capaz de influenciar o curso da gravidez, do trabalho de parto, do parto propriamente dito e da adaptação entre mãe e bebê no período pós-parto. $\mathrm{O}$ medo do parto pode ser considerado a expressão de vários sentimentos de ansiedade alimentados durante a gestação, e está associado ao aumento do risco de a gestante ter uma experiência negativa do parto (Areskog, Uddenberg \& Kjessler, 1984). A dor é outro fator comumente relacionado à experiência do parto e, apesar de autores como Salmon e Drew (1992) afirmarem que pouco é conhecido sobre os fatores que determinam a experiência subjetiva feminina do parto, seus estudos demonstram que um parto sem dor não é sinônimo de satisfação com a experiência. Já segundo Waldenström (1999), dor e ansiedade durante o trabalho de parto estão associados a uma experiência de parto negativa. Para Lebovici (1987), as relações entre a dor e a ansiedade são recíprocas: a dor acentua a ansiedade, e a ansiedade incrementa a dor. A dor é fonte de ansiedade, pois provoca fantasias em relação ao corpo e sua integridade. Ela também reaviva as vivências de punição e de perseguição, provocando, segundo Lebovici (1987) uma regressão das libidos objetal e narcísica, intensificando o investimento no próprio corpo. A dor também está ligada ao medo da morte. Entretanto, a dor do parto tem uma finalidade, pois o bebê aparece para justificá-la, recompensando a mãe pelo esforço.

O contato imediato com o filho após o nascimento é outro fator que parece estar associado a uma vivência mais positiva do parto. Por exemplo, Mercer e colaboradores (1983) encontraram que mulheres que tiveram contato precoce com seu bebê saudável logo após o nascimento apresentaram impressões mais positivas da experiência do parto. A interação com o filho foi apontada pelos autores como a segunda variável mais importante para predizer o tipo de vivência do parto, ficando atrás apenas do apoio emocional prestado pelo companheiro. Os acontecimentos que cercam o trabalho de parto e o nascimento do bebê parecem afetar as primeiras relações da mãe com seu filho. $\mathrm{O}$ tipo de atendimento prestado à mulher nos momentos que cercam o parto é fundamental para sua confiança na própria capacidade de ser mãe e de cuidar de outro ser humano. Para Klaus e Kennell (1992), ser valorizada e apoiada pode reforçar na mulher sentimentos de ser capaz e de poder assumir sua identidade materna. Portanto, a experiência do parto produz efeitos na auto-estima da mulher, podendo favorecer ou prejudicar sua disponibilidade emocional para com seu bebê imediatamente após o parto (Peterson, 1996). Segundo a autora, entre os fatores que contribuem para um senso positivo de si mesmas, podem ser citados: a participação ativa no processo do parto, inclusive nas tomadas de decisões que cercam este momento; a percepção de que seus sentimentos são aceitos e respeitados por seus cuidadores; a sensação de que estão realisticamente preparadas para o parto e para a maternidade, com um senso de domínio de suas estratégias de enfrentamento; que seja vista como alguém que está fazendo o melhor que pode; que tenha amplas oportunidades de expressar seus sentimentos sobre a maternidade, sobre o próprio nascimento, sobre os partos da sua própria mãe e sobre qualquer experiência prévia de gravidez e parto.

Os estudos acima revelam a complexidade deste momento na vida das mulheres, que transcende a sua dimensão primeira a médica - e apresenta repercussões psíquicas, sociais e culturais. Do ponto de vista psicológico, o parto constitui-se em um momento em que as expectativas e ansiedades que acompanharam a gestante ao longo de meses acabam por tomar uma dimensão real, confirmadora ou não das esperanças e medos que cercam o parto. Parte-se do pressuposto de que o parto é um evento que acompanha todo o processo de gestação e puerpério, uma vez que ele já é antecipado na gravidez sob a forma de expectativas, e continua sendo referido após sua conclusão, na forma de lembranças e sentimentos que acompanham a mãe, fazendo parte de sua história. Nesse sentido, o presente estudo tem como objetivo investigar as expectativas de gestantes com relação ao parto e, num segundo momento, os sentimentos destas mulheres em relação à vivência do próprio parto.

\section{Método}

\section{Participantes}

Participaram deste estudo 28 mulheres primíparas, sem problemas de saúde, com idades entre 20 e 37 anos ( $m=28$ anos; $d p=5,3$ anos). Todas viviam com o pai do bebê, eram de níveis sócio-econômicos variados, residiam na região metropolitana de Porto Alegre e utilizaram o serviço público de saúde no momento do parto. Dos casos investigados, 13 mulheres tiveram parto por via vaginal, sendo que 3 utilizaram medicação para indução, enquanto que, das 15 mulheres que tiveram parto por cesareana, apenas 3 marcaram o procedimento com antecedência. Os bebês, de ambos os sexos, não apresentaram problemas de saúde após o nascimento. Em termos de escolaridade, as gestantes variaram entre ensino fundamental incompleto $(11 \%)$ e completo $(7 \%)$, ensino médio incompleto $(3 \%)$ e completo (21\%), superior incompleto $(21 \%)$ e completo $(36 \%)$. Houve uma variação similar em termos do status ocupacional da profissão das gestantes, variando de profissões de "baixo status" (15\% das mães estavam em profissões classificadas de 1 a 4 na escala de Hollingshead, 1975), "status médio" (40\% em profissões 
classificadas de 5 a 6), e de "alto status" (45\% em profissões classificadas de 7 a 9).

As participantes fazem parte da amostra do projeto intitulado Estudo Longitudinal de Porto Alegre: Da Gestação à Escola (Piccinini, Tudge, Lopes \& Sperb, 1998), que acompanha aproximadamente 100 famílias de diferentes configurações, com idade, nível sócioeconômico e escolaridade variados. Para o presente estudo foram consideradas apenas a primeira fase de coleta de dados, durante a gestação, e a segunda fase, após o parto, quando o bebê tinha 3 meses de vida.

\section{Procedimentos e Instrumentos}

Durante a gestação, as mães foram contatadas nos hospitais e informadas sobre os objetivos e procedimentos do estudo. Aquelas que concordaram em participar assinaram um Termo de Consentimento Livre e Esclarecido. Nessa mesma ocasião, as participantes responderam a Entrevista de contato inicial(GIDEP, 1998a), e também a Entrevista de dados demográficos (GIDEP, 1998b). A primeira entrevista visava a investigar se a gestante atendia às características exigidas para a composição da amostra, e a seguinte foi utilizada para obter informações demográficas adicionais, como idade, escolaridade, estado civil, religião, ocupação e grupo étnico.

Posteriormente, foi combinado um encontro na residência da gestante, para que fosse realizada a Entrevista sobre a gestação e as expectativas da gestante (GIDEP, 1998c). Esta entrevista, semi-estruturada, com questões abertas, teve como objetivo investigar o contexto em que se deu a gravidez da participante, bem como seus sentimentos e expectativas em relação ao bebê, ao parto e à maternidade. Para o presente estudo, foi analisado apenas o relato das mães acerca das expectativas em relação ao parto.

A etapa seguinte da coleta de dados foi realizada no terceiro mês de vida do bebê, quando as mães responderam à entrevista semi-estruturada denominada Entrevista sobre a experiência da maternidade (GIDEP, 1999), cujo objetivo foi de investigar, através de questões abertas, aspectos da experiência da maternidade e desenvolvimento do bebê $\hat{~}^{2}$. Neste estudo, especial atenção foi dada aos relatos sobre o parto.

\section{Resultados}

Análise de conteúdo qualitativa (Bardin, 1977; Laville \& Dionne, 1999) foi utilizada para se examinar as expectativas das gestantes sobre o parto, e os sentimentos das mães sobre a experiência do parto no $3^{\circ}$ mês de vida do bebê. Examinaram-se ainda as expectativas e sentimentos maternos com relação ao tipo de parto realizado, normal ou cesárea. Por fim, investigou-se a relação entre as expectativas e os sentimentos das mães em relação ao parto.

\section{Expectativas em relação ao parto}

Quanto às expectativas das gestantes em relação ao parto, foi realizada uma primeira análise de conteúdo qualitativa priorizando a

\footnotetext{
${ }^{2}$ Além destes instrumentos outros também foram utilizados na gestação e no $3^{\circ}$ mês de vida do bebê, para coletar dados sobre o pai e o casal (cf. Piccinini \& cols., 1998). Mas os dados destes instrumentos não foram considerados no presente estudo.
}

natureza positiva ou negativa dos relatos, que foram classificados em três categorias temáticas: 1) expectativas positivas; 2) expectativas negativas; e, 3) expectativas tanto positivas como negativas. Uma segunda análise priorizou o fato de as expectativas referirem-se às próprias mulheres ou ao seu bebê, que também foram classificadas em três categorias: 1) expectativas em relação a si própria; 2) expectativas em relação ao bebê; $\mathrm{e}, 3)$ expectativas tanto em relação a si própria como ao bebê. Duas das autoras do presente artigo classificaram, separadamente, os relatos das mães e, em caso de discordância, recorreu-se a um terceiro colega. Apresenta-se, a seguir, a descrição das categorias, ilustrada pelos relatos das mães. Com relação às expectativas positivas sobre o parto, apenas uma gestante fez um relato classificado nesta categoria, que se referia à confiança no atendimento médico que receberia no momento do parto: $o$ meu médico sempre me tranqüiliza, ele já tem uma equipe e as pessoas que estiverem lá vão tentar fazer o melhor (M11) ${ }^{3}$.

Com relação às expectativas negativas em relação ao parto, destacam-se o receio de que o bebê nasça prematuro: $A$ minha única preocupação é que ele naşa antes (M21); com problemas de saúde: A gente sempre se preocupa se vai nascer normal, né. Até, a gente fez um monte de ecografia. Os médicos sempre disseram que ela, que é minina né, que ela estava normalz̨inha. Mas a gente sempre se preocupa né, vê na tevê, coisas de crianças com problemas. Sempre tem preocupação, né (M14); preocupação com a dor: É que, em relação, assim, eu tenho medo que dói, então o meu medo maior é que vai doer bem mais pra sair o bebê, até eu tenho médico sexta-feira e vou conversar sobre isso com ele, que o meu medo maior acho que é esse (M9); insegurança quanto ao atendimento que receberão: eu tenho inseguranças do tipo assim, será que eu confio na minha médica? (M15); medo de ser incapaz: este é meu único medo! Que na hora do parto eu não saiba como agir! Este é meu medo! (M25); receio de não reconhecer os sinais do parto: eu tenho um pouco de medo assim, da dor, assim, da hora, se en vou saber que é a dor [do parto], até boje en falei pra doutora se en vou saber que é contração o que eu estou sentindo. (M26); medo de morrer: eu tenho medo... Deus me livre, de morrer no parto (M23); medo de não ter controle sobre o parto: porque tem que ser tudo programado, sabe, senão assusta, não sei lidar com situacões novas, urgências, tipo urgências.... Tá sendo difícil assimilar o medo do parto, porque o medo do parto é o pior medo (M20); e, medo das mudanças ocasionadas pelo nascimento do bebê: Agora começo a pensar que quando ela nascer eu tenho que me dedicar, porque ontem à noite...olha o pensamento, ontem à noite eu tava assim... essa paz vai acabar, eu disse que vai acabar essa calma, e não vai mais ser só eu, vai sempre ter alguém na casa que vai depender de ti sempre, sempre, sempre (M20).

Por fim, algumas gestantes mencionaram simultaneamente expectativas positivas e negativas em relação ao parto, tais como: Pois é, sabe que nessa última semana que eu pensei mais nisso, eu não sei eu sempre tive a idéia que ia ser tudo muito fácil pra mim, talvez porque a minha mãe teve quatro filhos, todos os quatro de parto normal, né e sempre foram bem fáceis pra ela. A minha irmã mais velha também teve parto normal e não sei, parece, a minha impressão é que vai ser uma coisa rápida,

${ }^{3}$ A letra e o número entre parênteses identificam a participante que forneceu o relato. 
fácil, não sei, não me preocupo, me preocupo um pouco assim, é antes, os preparativos, ter que ir pro hospital ou a lavagem intestinal que eles fazem me assusta um pouquinho, mas eu nem falei muito com a médica sobre isso, ela disse pra en ficar tranqüila que vai ser parto normal, tem tudo pra ser parto normal (M16).

Após a classificação das expectativas das gestantes nas categorias descritas acima, verificou-se que, de todas as que relataram suas expectativas $(n=19)$, a grande maioria delas enfatizou expectativas negativas em relação ao parto (14 gestantes; $74 \%$ ). Apenas uma relatou expectativas positivas, enquanto quatro delas (21\%) relataram expectativas tanto positivas quanto negativas. Nove gestantes não referiram expectativas sobre o parto, o que pode estar associado mais ao medo e ansiedade por este momento desconhecido, do que a uma real ausência de expectativas.

As expectativas em relação ao parto também foram classificadas de acordo com o fato de se referirem às próprias mulheres, ao bebê, ou a ambos. $\mathrm{Na}$ categoria, expectativas em relação a si próprias, foram classificados relatos como: $A$ minha única preocupação é se en precisar de anestésico, en trabalhei a minha cabeça, en trabalhei tudo em função de eu ter um parto normal. Se en precisar de cesárea en sei que eu corro risco (M7); Às vezes en fico assim, meio insegura, ai será que vai ser ou parto normal ou cesárea, essas coisa, né, mas do contrário não, ... se eu não conseguir, se eu não conseguir, se não conseguir ser parto normal vai ter que ser uma cesárea, né (M14). Na categoria expectativas em relação ao bebê, foram classificados relatos como: $A$ gente sempre se preocupa se vai nascer normal, né (M14); Quero que ele [o bebê] nasça bem. E que seja saudável (M17). Por fim, na categoria expectativas em relação a si próprias e ao bebê, foram classificados relatos como: Mais assim de sofrer muito naquele momento, ou de ela nascer anormal, embora eu saiba, todos os exames que eu já fiz vários, o do coração dela, en sei que ela está perfeitinha, até aonde se pode ver. Mas eu tenho medo disso também, e eu tenho medo de não conseguir dar conta de tudo (M15).

Após a classificação das expectativas das gestantes nestas categorias, verificou-se que, de todas as que relataram suas expectativas $(n=19)$, a grande maioria delas relatou expectativas em relação a si próprias (12 gestantes; 63\%). Apenas duas relataram expectativas em relação ao bebê, enquanto cinco delas (26\%) relataram expectativas em relação ao si próprias e ao bebê.

\section{Experiência do parto}

Quanto aos sentimentos em relação ao próprio parto depois de transcorridos 3 meses do nascimento do bebê, também foi realizada uma primeira análise de conteúdo qualitativa priorizando a natureza positiva ou negativa dos relatos, classificados em três categorias: 1) sentimentos positivos em relação ao parto; 2) sentimentos negativos em relação ao parto; e, 3) sentimentos tanto positivos como negativos. Uma segunda análise dos relatos priorizou o fato de os sentimentos referirem-se às próprias mulheres ou aos seus bebês, que também foram classificados em três categorias: 1) sentimentos em relação a si própria; 2) sentimentos em relação ao bebê, e, 3) sentimentos tanto em relação a si própria como ao bebê. Para fins de classificação das respostas nestas categorias, procedeu-se do mesmo modo já descrito acima. Entre os sentimentos positivos em relação ao parto, as mães destacaram o fato de ter sido um momento emocionante: Foi muito emocionante, né, assim, foi uma coisa bem... e eu tava muito calma, muito tranqüila, assim, tava bem... calma (M10); maravilhoso: É uma experiência maravilhosa (M6); ter sido um parto fácil ou rápido: A gente foi pro hospital, e já fez anestesia, né, peridural, aquela, e... às 6 e 45 ela nasceu, foi um parto bem rápido. (M10); sentimentos positivos em relação à assistência médica e de enfermagem: $A$ assistência médica foi das melhores que a gente já teve (M19); a emoção do primeiro encontro com o filho: O momento mais assim, foi filmado, ai, foi muito, muito, muito..., bá, eu acho que nunca senti outra emoção na minha vida maior que quando eu ouvi o choro dela, foi..., bá, demais. Assim, eu acho que não existe palaura pra, pra...pra dá um significado pra do que foi essa experiência, foi muito legal (M15).

As participantes também referiram sentimentos negativos em relação ao parto, tais como ter sentido muita dor: Ab o parto, nossa senhora... eu ainda to naquele choque... en achei assim horrivel, a pior dor da vida. Eu pensava assim na hora que si um caminhão me atropelasse não iria doer tanto (M1); ter sofrido durante a experiência: Ela me disse que como eu tava muito tempo esperando e não tava dando dilatação nenbuma ela ia botar o soro pra fazer a indução, né. Ai sim que en comecei a sofrer, porque aquele soro é horrivel, porque se fosse um negócio que fosse vim gradativo não, mas se fosse mais rápido que tu já começasse a colocar e em seguida começasse [a nascer], mas não aquilo vai ficando, tu vê, era uma hora da tarde e eu fui ganhar as 10 horas da noite, então aquilo foi sacrificando, né (M4); ter sido um parto demorado: Não, não foi rápido. É, foi assim, eu tive as primeiras dores, aquelas contraçöes bem fortes assim na sextafeira, às 5 horas, então aí, só no domingo de manhã que eu voltei [para o hospital], aí cheguei lá e já tava com quatro dedos de dilatação, aí me baixaram, aí, só que demorou muito assim, que a bolsa só rompeu às 9 da noite de domingo, e ele só nasceu às 7 da manhã de segunda-feira. Dai das nove, depois que rompen a bolsa, das 9 horas da noite de domingo, foi bem, aquelas dores mesmo assim, que dá vontade de gritar, foi assim, demoron das 9 até as 7, bem demorado (M8); ou difícil: O meu parto foi difícil (M5); ter sentido medo da anestesia: Eu tinha um medo da anestesia, do anestesista, sei lá, eu queria ganhar de parto normal né. Porque aí eu tinha muito medo da anestesia assim, a gente não sente nada no fim né, eu tinha muito medo, muito medo da anestesia, sei lá porque eu tinha medo (M14); ter experimentado sentimentos de incapacidade: No meu caso en achei que por eu ser mais velha já estava mais preocupada com aquilo, né pra mim foi mais, emocionalmente foi mais complicado, né, porque quando estourou a bolsa de manhã, aquela coisa toda e eu me assustei, que eu disse: E agora, né, o que eu faço, né, o que en tenho que fazer, né (M4); medo da morte: As enfermeiras estavam muito preocupadas com a hemorragia ... en tava preocupada com aquilo [hemorragia], mas pensei, bom, ela já tá no mundo, né, agora o que tiver que acontecer comigo, ela vai ter quem crie ela, se por acaso eu não conseguir, né, se eu ficar muito mal, né, porque en tava assim, achava que eu tava muito mal, né (M4), e sentimentos negativos em relação à assistência médica e/ou de enfermagem: Ai assim que eu me senti um pouco magoada assim, um pouco porque eu tava muito sensivel né, e a enfermeira disse assim: 'sai, sai pra lá pra maca, anda, sobe', não sei o que, porque eu acho que ela ficon braba que eu fiz as necessidades na cama, não sei se foi isso, sabe, ai eu fui me arrastando, eu me senti que nem um bicho, sabe, acuado, né, que eu tava toda sensivel e elas me, sabe, me enxotando (M4).

Algumas participantes referiram ainda sentimentos positivos $e$ negativos, sendo que o relato inicial foi composto por sentimentos 
negativos, mas posteriormente compensados por sentimentos positivos: O parto até que foi um pouco assim, como é que eu vou te dizer, meio abalado, porque foi induzido, né e aí eu não consegui a indução, não teve as dilatações ai foi para a cesárea, foi cansativo, mas também, porque ele já nasceu um pouquinho rouxinho e tudo, mas também quando, depois foi as mil maravilhas, né (M12).

Após a classificação dos relatos sobre o parto, descritas nas categorias acima, verificou-se que, de todas as que relataram sentimentos sobre o parto $(n=24)$, a maior parte referiu-se a sentimentos positivos (10 gestantes; 42\%). Outras nove participantes relataram sentimentos negativos $(37 \%)$, enquanto cinco delas $(21 \%)$ relataram tanto sentimentospositivos, quanto negativos. Quatro mães não fizeram referência aos sentimentos sobre a experiência do parto.

A segunda análise sobre a experiência do parto revelou que algumas participantes referiram sentimentos em relação a si próprias, tais como: Eu tava muito calma, muito tranqüila, assim, tava bem... calma, assim, parecia assim, eu sentia que tava correndo tudo bem, que eu não tinha que me preocupar (M10). Apenas uma participante referiu exclusivamente sentimentos em relação ao bebê: Não... não senti nada, nada, nada... eu não sei nem o que é dor de parto... Mas fui por causa que a bolsa estourou! Ai en esperei até as $2 \mathrm{~b}$ da tarde para fazer o parto... desde as 10 ... dai tiraram ela rapidamente, ai depois viram que ela tava tudo normal! Tava bem, ai colocaram ela perto de mim (M25). Outras mulheres referiram simultaneamente sentimentos em relação a si próprias e ao bebê, como: A gente foi pro hospital, assim, en tava bem tranqüila assim. Eu tava super tranqüila em relação a ele [bebê] também. Fiquei em casa de manhã fui pro hospital, cheguei no hospital, comecaram todos os preparativos fiquei na sala, rezei, chegou a hora eu não tinha aquele pânico, aquele medão, sabe? E ai eu tava bem tranqüila ... Ele nasceu roxinho cor de wva, como eu digo. E eu não sabia quepoderia ser um problema depois né, que é desconhecimento da gente (M17).

Após esta segunda classificação dos sentimentos das gestantes sobre o parto, verificou-se que, de todas as que relataram seus sentimentos $(n=24)$, a maioria relatou sentimentos em relação a si próprias (13 gestantes; 54\%). Apenas uma relatou exclusivamente sentimentos em relação ao bebê, enquanto 10 delas (42\%) relataram expectativas em relação a si próprias e ao bebê.

\section{Quanto ao tipo de parto}

A Tabela 1 apresenta a freqüência e porcentagem de cada tipo de expectativa em relação ao parto relatada pela gestante, e

Tabela 1

Expectativas e Sentimentos em Relação ao Parto

\begin{tabular}{|c|c|c|c|c|}
\hline & & \multicolumn{3}{|c|}{ Tipo de parto } \\
\hline & & $\begin{array}{l}\text { Normal } \\
n=13\end{array}$ & $\begin{array}{l}\text { Cesareana } \\
n=15\end{array}$ & $\begin{array}{l}\text { Total } \\
N=28\end{array}$ \\
\hline \multirow[t]{4}{*}{ Expectativas } & Positivas & - & $1(7 \%)$ & $1(3 \%)$ \\
\hline & Negativas & $6(46 \%)$ & $8(53 \%)$ & $14(50 \%)$ \\
\hline & Positivas e negativas & $2(15 \%)$ & $2(13 \%)$ & $4(14 \%)$ \\
\hline & Não refere & $5(38 \%)$ & $4(27 \%)$ & $9(32 \%)$ \\
\hline \multirow[t]{4}{*}{ Sentimentos } & Positivos & $4(31 \%)$ & $6(40 \%)$ & $10(35 \%)$ \\
\hline & Negativos & $5(38 \%)$ & $4(27 \%)$ & $9(32 \%)$ \\
\hline & Positivos e negativos & $3(23 \%)$ & $2(13 \%)$ & $5(18 \%)$ \\
\hline & Não refere & $1(8 \%)$ & $3(20 \%)$ & $4(14 \%)$ \\
\hline
\end{tabular}

o tipo de parto realizado. Também apresenta os sentimentos relatados pelas gestantes em relação ao parto, 3 meses depois de sua ocorrência. Entre as 14 gestantes que referiram expectativas negativas sobre o parto durante a gestação, 53\% foram submetidas posteriormente à cesareana, com duas cirurgias agendadas previamente e, $46 \%$ tiveram parto por via vaginal. Já as 4 participantes que referiram simultaneamente expectativas positivas e negativas sobre o parto, duas tiveram parto normal e duas, cesareana. A participante que verbalizou expectativa positiva em relação ao parto teve, mais tarde, parto cesáreo. E, entre as nove mulheres que não referiram expectativas sobre o parto durante a gestação, 5 tiveram parto normal e quatro, cesareana. Em relação aos sentimentos verbalizados sobre o parto 3 meses depois do nascimento do bebê, das 13 mães que realizaram parto normal, 38\% referiram sentimentos negativos, 31\% mencionaram sentimentos positivos e $23 \%$ sentimentos positivos e negativos. Das 15 mulheres que realizaram parto cesárea, $40 \%$ referiram sentimentos positivos, $27 \%$ sentimentos negativos e 3\% sentimentos negativos e positivos. Das participantes que não referiram sentimentos, apenas uma teve parto normal, sendo que três realizaram cesareana.

O teste não-paramétrico $\mathrm{McNemar}$, indicado para medidas repetidas de uma mesma amostra, foi utilizado para se examinar eventuais diferenças entre as expectativas em relação ao parto relatadas pela gestante e os seus sentimentos sobre o parto depois de decorridos 3 meses. Este teste é adequado para detectar mudanças nas respostas de participantes antes e depois de determinada intervenção. Ele examina quantos participantes apresentaram o mesmo tipo de resposta antes e depois da intervenção (Ex.: expectativa positiva e sentimentos positivos ou expectativas negativas e sentimentos negativos) e quantos mudaram as respostas (Ex.: expectativa negativa e sentimentos positivos). Ele só examina respostas dentro de uma mesma categoria. Como os dados desta amostra não preenchem todos os critérios para a utilização de um teste não-paramétrico padrão para medidas repetidas, optou-se pela realização do teste exato, com o objetivo de obter resultados mais precisos.

Os resultados revelaram uma mudança significativa entre as expectativas positivas em relação ao parto e os sentimentos positivos em relação à experiência do parto após 3 meses $(p=0,012)$. Enquanto na gestação apenas uma mãe revelou expectativas positivas, 
no $3^{\circ}$ mês após o parto 10 mães relataram sentimentos positivos. Tal resultado permite afirmar que existiu uma diferença significativa entre as expectativas positivas e os sentimentos positivos, indicando que expectativas positivas em relação ao parto na gestação não estiveram relacionadas a sentimentos positivos sobre o mesmo, 3 meses depois de sua ocorrência. Também foram realizadas comparações entre as demais categorias, sendo que nenhuma outra relação entre as medidas apontou a mesma descontinuidade nas respostas. A análise descritiva dos dados revela que a participante que referiu expectativas positivas sobre o parto não referiu nenhum tipo de sentimento sobre o parto após 3 meses. Já das 14 participantes que referiram expectativas negativas, $43 \%$ continuaram referindo sentimentos negativos sobre a experiência, mas $29 \%$ mudaram seu discurso, referindo sentimentos positivos sobre o parto. Por fim, das participantes que referiram tanto expectativas positivas, quanto negativas, $50 \%$ referiram apenas sentimentos negativos sobre o parto $\mathrm{e}$, entre as mulheres que não referiram expectativas sobre o parto durante a gestação, a maioria (56\%) referiu sentimentos positivos sobre a experiência.

\section{Discussão}

Os resultados do presente estudo apóiam a expectativa inicial de que o parto constitui um evento que perpassa todo o processo de gestação e puerpério, marcando profundamente a história das mulheres. Ele já é antecipado na gravidez sob a forma de expectativas, e continua sendo referido posteriormente, na forma de lembranças e sentimentos que acompanham a mãe. De um lado, ele exacerba intensas fantasias e ansiedades frente a um momento muito esperado, mas cercado pelo imprevisível, como relatado nas expectativas das mães do presente estudo. Por outro lado, a sua vivência marca profundamente a vida das mulheres, seja pelas emoções positivas ou negativas experimentadas. Os relatos apresentados acima retratam a intensidade dos sentimentos que cercam este momento da maternidade, com possíveis implicações para o relacionamento mãebebê e futuro desenvolvimento da criança.

Examinando conjuntamente os achados sobre as expectativas das gestantes, percebe-se que mais da metade das participantes referiu expectativas negativas em relação ao parto, com apenas uma gestante relatando aspectos positivos. É plausível se pensar que a ansiedade do $3^{\circ}$ trimestre contribua para a formulação de expectativas negativas sobre o parto, incluindo medo da dor e dos procedimentos obstétricos, insegurança quanto ao atendimento eà própria capacidade de dar à luz, além do medo das mudanças que serão ocasionadas pelo nascimento do bebê.

De uma forma geral, percebeu-se uma tendência das gestantes de referirem de maneira escassa suas expectativas sobre o parto, sendo que nove delas nem mesmo revelaram suas expectativas. Isto pode estar particularmente relacionado ao momento da gestação em que a coleta de dados foi realizada, o $3^{\circ}$ trimestre. Para alguns autores, este período é marcado pelo aumento da ansiedade, em função da proximidade do parto. A apreensão frente às mudanças na rotina $\mathrm{da}$ vida com a chegada do bebê tendem a tornar aguda a ansiedade nos dias que antecedem a data prevista para o nascimento. Os sentimentos são, em geral, contraditórios: querer ter o bebê e terminar logo a gravidez e, ao mesmo tempo, a vontade de prolongar a gestação para adiar a necessidade de novas adaptações exigidas com a chegada do filho (Brazelton \& Cramer, 1992; Maldonado, 1994; Szejer \& Stewart, 1997). Assim, o não falar sobre o parto durante a gestação pode estar evidenciando uma tentativa dessas mulheres de se defenderem da ansiedade típica do $3^{\circ}$ trimestre de gestação. No presente estudo, mesmo as que não falaram sobre o parto antes de sua realização referiram, após o mesmo, sentimentos em relação a essa experiência, o que apóia a idéia de que as eventuais dificuldades de falar sobre o parto são particularmente comuns aos meses que $\mathrm{o}$ antecedem.

A escassez de expectativas específicas em relação ao bebê, referidas no $3^{\circ}$ trimestre de gestação, parece apoiar as idéias de Stern (1997), que relatou mudanças nas representações maternas sobre o bebê ao longo da gestação. Entre o $4^{\circ}$ e o $7^{\circ}$ mês de gestação haveria um rápido aumento na riqueza, quantidade e especificidade das representações sobre o feto. Contudo, essa crescente elaboração sobre o bebê não se manteria até o nascimento. No último trimestre de gestação - período em que foi realizada a primeira fase da coleta dos dados do presente estudo - ocorreria uma espécie de anulação das representações sobre o bebê, as quais diminuiriam e se tornariam progressivamente menos delineadas, menos ricas e menos específicas. Esse movimento teria a função de proteger o bebê e a própria mulher da potencial discordância entre o bebê real e um bebê que foi representado, por vezes, de forma específica durante a gestação. Dessa forma, a mãe evitaria que, no momento do nascimento, a situação real estivesse demasiadamente ligada a uma situação passada, para que ela e o bebê pudessem começar uma nova forma de relação. Estas considerações de Stern podem contribuir para entender as manifestações limitadas das mães em relação ao bebê. Além disto, pode-se pensar que a ansiedade e as preocupações quanto à saúde e até a sobrevivência do bebê durante o parto devem contribuir para que as mães diminuam suas elaborações e representações sobre o bebê.

Já com relação aos achados sobre os sentimentos em relação ao parto, 3 meses depois do ocorrido, percebe-se que alguns relatos foram marcados por uma particularidade: inicialmente havia elevada incidência de sentimentos negativos e, depois do parto, aumentaram os sentimentos positivos. Isto pode estar sugerindo que o parto foi, na prática, melhor do que o esperado pelas gestantes, ou então pode estar relacionado com uma tentativa de minimizar a culpa por não ter gostado da experiência ou, ainda, a tentativa de evitar sua depreciação.

O parto com dor seria sinônimo de uma má experiência, já que a crença social sugere que o que é bom não incluiria dor (Peterson, 1996; Szejer \& Stewart, 1997). Segundo estes autores, muitas vezes, as mulheres são levadas até a mentir sobre a dor nos seus relatos sobre o parto para evitar sua desvalorização. Entretanto, a dor pode estar associada a uma vivência positiva (Szejer \& Stewart, 1997). A cultura fundada sob os preceitos do Cristianismo impõe que a boa mãe é aquela que sofre dando à luz seus filhos, pois, 
afinal, a mulher foi destinada a parir com dor, segundo palavras biblicas. Tendo em vista este fator cultural, a dor do parto pode até ser experimentada, ou pelo menos referenciada, como algo positivo. De qualquer modo, é necessário ressaltar que, neste trabalho, a referência à dor foi categorizada como um sentimento negativo em relação ao parto, mas tal classificação necessitaria ser melhor investigada, levando em consideração possíveis variações na representação cultural da dor do parto para as mulheres.

Os resultados mostraram ainda que as participantes relataram muito mais expectativas em relação a si próprias do que em relação ao bebê. Isto parece corroborar as idéias de Peterson (1996) de que o parto é um evento feminino, apesar de o bebê por vezes ser visto como o ator principal, relegando a mulher ao segundo plano. Geralmente, os profissionais responsáveis pela assistência de saúde não entendem a necessidade das mulheres de falarem sobre o parto, principalmente se deram à luz uma criança saudável. Segundo a autora, ajudá-las a integrar a experiência é fundamental para garantir sua integridade psíquica, apesar de tal fato parecer insignificante para todos ao seu redor, inclusive para a própria mulher. Quando ela tem a oportunidade de falar sobre o parto, como a que foi dada no presente estudo, é possível identificar suas fortes emoções com sentimentos que vão além da descrição dos fatos ocorridos.

Após o nascimento do bebê, os resultados apontaram uma tendência das participantes a referirem sentimentos negativos sobre o primeiro encontro com o filho, principalmente associados à sua aparência física. Tais sentimentos podem estar refletindo a discrepância entre o bebê imaginário, alimentado pela mulher durante toda a gestação, e o bebê real, recém-nascido (Brazelton \& Cramer, 1992). Segundo estes autores, o nascimento de um filho acarreta uma revolução psicológica na mulher, pois ela é chamada a desempenhar diversas tarefas importantes. Entre elas, pode-se citar o luto pela perda da criança imaginária e perfeita e a adaptação às características específicas do filho real, além da adaptação a um novo ser que provoca sentimentos de estranheza.

Por fim, examinando-se longitudinalmente os achados, verificaram-se algumas mudanças nas expectativas sobre o parto, o tipo de parto realizado e os sentimentos a ele associados. Durante a gestação, as participantes verbalizaram um número maior de expectativas negativas do que positivas em relação ao parto. Contudo, as expectativas negativas parecem não se confirmar nas respostas de muitas das mães, 3 meses após o parto, quando parece ter havido um maior equilíbrio entre as verbalizações positivas e negativas. Apesar de ter havido esta mudança, os resultados tendem a apoiar a idéia de que mulheres que possuam expectativas negativas sobre o parto terão uma vivência menos satisfatória sobre o mesmo.

A análise estatística corrobora o exposto acima, uma vez que não identificou mudanças significativas entre as expectativas negativas em relação ao parto e os sentimentos negativos em relação à vivência, relatados 3 meses depois. Enquanto na gestação metade das mães tinham expectativas negativas sobre o parto, muitas delas continuaram a relatar sentimentos negativos sobre ele. Contudo, houve uma mudança significativa entre as expectativas positivas em relação ao parto, e os sentimentos positivos em relação ao parto. Enquanto na gestação apenas uma mãe tinha expectativa positiva sobre o parto, 3 meses depois de sua realização, muitas mães relataram sentimentos positivos. A ansiedade e temor sobre o parto relatados por várias das gestantes parecem ter sido re-significados com a própria experiência, que acabou sendo vista por várias delas com sentimentos positivos.

Quanto ao tipo de parto realizado e os sentimentos a ele associados, de modo geral, não foram identificadas diferenças marcantes nas respostas das mães. Para Szejer e Stewart (1997), o parto cesáreo tende a ser vivido por algumas mulheres apenas como uma cirurgia, diminuindo sua importância. Contudo, contrário ao que se esperaria, a cesareana esteve associada a uma incidência um pouco maior de sentimentos positivos do que de sentimentos negativos. Diferenças menos expressivas ainda foram encontradas sobre os sentimentos positivos e negativos com relação ao parto normal. Cabe destacar que o pequeno número de participantes em cada grupo não permite estabelecer conclusões e novos estudos se fazem necessários. De qualquer modo, os resultados do presente estudo não corroboram as sugestões de que o parto normal estaria associado com uma vivência positiva da experiência, enquanto a cesarerana estaria associada com vivências negativas.

Tomados em conjunto, os resultados do presente estudo retratam a complexidade de emoções associadas a este momento marcante na vida das mães, que é o parto. Na verdade, sua importância e implicações transcendem os poucos minutos ou, por vezes, horas de duração do parto. Ele é ansiosamente esperado, tanto pelas possíveis complicações que dele advém, como por marcar o primeiro encontro com o bebê real. Os achados do presente estudo mostram claramente suas repercussões ainda no $3^{\circ}$ mês após sua realização, e provavelmente, como enfatiza a literatura, se estende por toda a vida da mulher.

Neste sentido, é muito importante que os profissionais de saúde se sensibilizem sobre a importância deste momento. Qualquer deslize na relação gestante-profissional, como relatada por algumas mães do presente estudo, pode exacerbar sentimentos negativos, tendo em vista a extrema sensibilidade que as parturientes apresentam nesta situação. Enquanto no diaa-dia do profissional tende a ser mais uma gestante dando a luz, para a mãe é a sua primeira vez e, para muitas, talvez o episódio mais marcante em toda sua vida. Assim, dada a importância deste momento, é possível se pensar que psicólogos, trabalhando nas maternidades, possam contribuir para promover condições adequadas para que gestantes e familiares passem sem tantas dificuldades por este momento. Esta atuação profissional se faz ainda mais relevante, quando lembramos que em inúmeras ocasiões o parto envolve risco tanto à gestante como ao bebê, sem falar nas vezes em que a gestante recebeu diagnóstico de malformação fetal. Nestas situações, que merecem ser abordadas em novos estudos, as ansiedades e conflitos ficam ainda mais 
acentuados do que os destacados no presente estudo, que envolveu partos sem risco.

\section{Referências}

Areskog, B., Uddenberg, N. \& Kjessler, B. (1984). Postnatal emotional balance in women with and without antenatal fear of childbirth. Journal of Psychosomatic Research, 28, 213-220.

Bardin, L. (1977). Análise de conteńdo.Lisboa: Edições 70.

Birksted-Breen, D. (2000). The experience of having a baby: A developmental view. Em J. Raphael-Leff (Org.), 'Spilt milk', perinatal loss and breakdowm (pp. 17-27). Londres: Institute of Psychoanalysis.

Brazelton, T. B. \& Cramer, B. G. (1992). As primeiras relaçẽes. São Paulo: Martins Fontes.

Cordeiro, S. N. \& Sabatino, H. (1997) A humanização do parto. Em M. Zugaib, J. J. Tedesco \& J. Quayle (Orgs.), Obstetrícia psicossomática (pp. 280-317). São Paulo: Atheneu.

DiMatteo, M. R., Morton, S. C., Lepper, H. S., Damush, T. M., Carney, M. F., Pearson, M. \& Kahn, K. (1996). Cesarean childbirth and psychosocial outcomes: A meta-analysis. Health Psychology, 15, 303-314.

Durik, A. M., Hyde, J. S. \& Clark, R. (2000). Sequelae of cesarean and vaginal deliveries: Psychosocial outcomes for mothers and infants. Developmental Psychology, 2(36), 251-260.

Fisher, J., Astbury, J. \& Smith, A. (1997). Adverse psychological impact of operative obstetric interventions: A prospective longitudinal study. Australian and Nen Zealand Journal of Psycbiatry, 31, 728-738.

Kitzinger, S. (1987). A experiência de dar à luz: São Paulo: Martins Fontes.

Klaus, M. H. \& Kennell, J. H. (1993) Pais-bebê: A formação do apego. Porto Alegre: Artes Médicas.

Laville, C. \& Dionne, J. (1999). A construção do saber. Porto Alegre: Artmed.

Lebovici, S. (1987). O bebê, a mãe e o psicanalista. Porto Alegre: Artes Médicas.

Lipson, J. G. \& Tilden, V.P. (1980). Psychological integration of the cesarean birth experience. American Journal of Orthopsychiatry, 50, 598-609.

Maldonado, M. T. P. (1994). Psicologia da gravidez: Petrópolis, RJ: Vozes.

Maldonado, M. T. P., Dickstein, J. \& Nahoum, J. C. (1996). Nós estamos grávidos. São Paulo: Saraiva.

Mercer, R. T., Hackley, K. C. \& Bostrom, A. G. (1983). Relationship of psychosocial and perinatal variables to perception of childbirth. Nursing Research, 32, 202207.
Peterson, G. (1996). Childbirth: The ordinary miracle: effects of devaluation of childbirth on women's self-esteem and family relationships. Pre and Perinatal Psychology Journal, 11, 101-109.

Grupo de Pesquisa em Interação Social, Desenvolvimento e Psicopatologia GIDEP (1998a). Entrevista de contato inicial. Instituto de Psicologia - UFRGS, Porto Alegre. Instrumento não-publicado.

Grupo de Pesquisa em Interação Social, Desenvolvimento e Psicopatologia GIDEP (1998b). Entrevista de dados demográficos. Instituto de Psicologia - UFRGS, Porto Alegre. Instrumento não-publicado.

Grupo de Pesquisa em Interação Social, Desenvolvimento e Psicopatologia GIDEP (1998c). Entrevista sobre a gestação e as expectativas da gestante. Instituto de Psicologia - UFRGS, Porto Alegre. Instrumento não-publicado.

Grupo de Pesquisa em Interação Social, Desenvolvimento e Psicopatologia GIDEP (1999). Entrevista sobre a experiència da maternidade. Instituto de Psicologia - UFRGS, Porto Alegre. Instrumento não-publicado.

Piccinini, C. A., Tudge, J., Lopes, R. Sperb, T. (1998). Estudo Longitudinal de Porto Alegre: Da Gestaģão à Escola. Instituto de Psicologia - UFRGS, Porto Alegre. Projeto de pesquisa não-publicado.

Raphael-Leff, J. (1997). Gravideæ: A bistória interior. Porto Alegre: Artes Médicas.

Salmon, P. \& Drew, N. C. (1992). Multidimensional assessment of women's experience of childbirth: Relationship to obstetric procedure, antenatal preparation and obstetric history. Journal of Psychosomatic Research, 36, 317-327.

Simkin, P. (1991). Just another day in a woman's life? Part I: Women's long-term perceptions of their first birth experience. Birth, 18, 203-210.

Simkin, P. (1992). Just another day in a woman's life? Part II: Nature and consistency of women's long term memories of their first birth experiences. Birth, 19, 6481.

Stern, D. (1997). A constelação da maternidade: O panorama da psicoterapia pais/bebê. Porto Alegre: Artes Médicas.

Soifer, R. (1992). Psicologia da gravide», parto e puerpério. Porto Alegre: Artes Médicas.

Szejer, M., \& Stewart, R. (1997). Nove meses na vida da mulber: Uma abordagem psicanalítica da gravidez e do nascimento. São Paulo: Casa do Psicólogo.

Tulman, L. J. (1986). Initial handling of newborn infants by vaginally and cesarean delivered mothers. Nursing Research, 35, 296-300.

Waldesntröm, U. (1999). Experience of labor and birth in 1111 women. Journal of Psychosomatic Research, 47, 471-482.
Recebido: 02/10/2003

$1^{a}$ Revisão: 29/01/2004

Aceite Final: 14/05/2004

Sobre os autores

Rita de Cássia Sobreira Lopes é Doutora pela University of London. É Professora do Programa de Pós-graduação em Psicologia do Desenvolvimento da Universidade Federal do Rio Grande do Sul.

Tagma Schneider Donelli é Aluna do Programa de Pós-graduação em Psicologia do Desenvolvimento da Universidade Federal do Rio Grande do Sul.

Carolina Mousquer Lima é Aluna do Programa de Pós-graduação em Psicologia do Desenvolvimento da Universidade Federal do Rio Grande do Sul.

César Augusto Piccinini é Doutor pela University of London. É Professor do Programa de Pós-graduação em Psicologia do Desenvolvimento da Universidade Federal do Rio Grande do Sul. 